\title{
Bed morphology near a finite patch of vegetation under emergent and submerged
}

\author{
conditions
}

\author{
Hyung Suk Kim* , Ichiro Kimura** and Yasuyuki Shimizu*** \\ *Ph. D. student Division of Field Engineering for Environment, Hokkaido University (North 13, West 8, Kita-ku, Sapporo, Hokkaido, \\ 060-8628) \\ ** Dr. of Eng. Associate Prof. Division of Field Engineering for Environment, Hokkaido University (North 13, West 8, Kita-ku, \\ Sapporo, Hokkaido, 060-8628) \\ *** Dr. of Eng. Prof. Division of Field Engineering for Environment, Hokkaido University (North 13, West 8, Kita-ku, Sapporo, \\ Hokkaido, 060-8628)
}

\begin{abstract}
The effect of a finite patch on flow and bed morphology in the open channel was investigated using laboratory experiment. Two flow conditions, which were below and above the threshold of sediment motion, were considered with various configurations. For flows below the threshold of sediment motion (case 1), the erosion took place primarily opposite the patch and near the leading edge, whereas for the other condition (case 2), sediment deposition was observed within and near the patch due to reduction of shear stress, which was strongly influenced by the flow blockage. For case 1 , the degree of scouring depth increased with the flow blockage, and as the submergence ratio increased, the scour depth decreased. For case 2, as the flow blockage increased or the obstruction ratio decreased, the deposition rate within and behind the patch decreased.
\end{abstract}

Key Words: Finite Patch, Bed Morphology, Laboratory Experiment, Open Channel

\section{Introduction}

Both riparian and aquatic vegetation in natural channels controls the mean and turbulent flow, and then affects sediment transport. In particular, submerged plants or partly-vegetated channels can create shear layers between vegetated and un-vegetated regions, and induce strong vortices (Choi and Kang, 2006). Furthermore, riparian and aquatic vegetation can considerably affect the suspended load and the bed load. Those encourage accumulation of sediment within the vegetated regions by reducing bed shear stress. Vegetation on the bank and floodplain can reduce sediment load from bank erosion, increasing the bank strength and the plant root as well as reducing the flow velocity (Millar, 2000).

For the first time, Bennett et al. (2002) conducted laboratory experiment using semi-circular model patches for the purpose of creating a degraded straight channel to meandering channel. The emergent model patches were alternatively placed in the straight channel to alter the flow patterns and they measured surface flow velocities by means of particle image velocimetry (PIV). The study described that the flow velocities are significantly accelerated opposite the model patches, and the magnitude of them is controlled by the model patch density. Leu et al. (2008) investigated effects of cutting riparian vegetation on hydrodynamic behaviors by means of a depth-averaged numerical model to propose a cutting method for reducing the risk of flooding during the growing season. Five cutting scenarios, i.e., the original, cutting along the main channel side, cutting the bank side, alternative cutting and reducing vegetation density, were tested and they suggested that the cutting along the main channel was the most effective scenario for flood controls. Zong and Nepf (2012) described the turbulent wake behind a finite model patch, which consisted of emergent circular array of cylinders and placed at the mid-channel. A von-Karman vortex was formed behind the circular patch due to the interaction of shear layers, and the vortex street was weakened as the solid volume fraction of the model patch became lower.

The altered flow direction and pattern by a finite patch can considerably influence sediment transport and bed morphology, so that an understanding of how partially grown or planted vegetation in the streams or rivers influences erosion and deposition patterns is strongly required. Bennett et al. (2008) 
performed the experiment and numerical simulations to investigate channel responses due to finite patches, which consisted of emergent and circular cylinders, in the straight compound channel based on the experiments conducted by Bennett et al. (2002). They showed that the channel change was significantly affected by vegetation density due to the magnitude of bank erosion and local scour pools opposite and near the patches, respectively, and numerical model could be used for long-term bed morphology with finite vegetation. However, they could not measure the bed elevation within the patch due to the limitation of experimental conditions. Bouma et al. (2007) investigated spatial sedimentation patterns within patches in an intertidal flat. They consisted of bamboo cans and two patch densities were tested. Over two-years monitoring in the field, higher sedimentation and erosion were observed in the dense patch, whereas for the low patch, there was no pronounced spatial patterns of erosion and deposition. Even though the flume experiment was also conducted, it was different from the field observation condition since there was the limitation of the flume width which in turn, was filled with bamboo cans over the whole width. For the purpose of stream restoration, Rominger et al. (2010) carried out a field scale experiment in a sand bed stream with meander bends and vegetation was added to point bars at the convex part of the meandering channel. They described that erosion was observed near the lateral edge of vegetation and thus it caused the removal of some added vegetation.

In general, as mentioned in the literature reviews, the patch density is a key parameter for clarifying the sediment erosion and deposition near the patch, whereas there are other un-investigated parameters related to bed morphology with finite patches of vegetation in the streams. Most previous studies investigated the channel response to rigid, emergent vegetation of varying patch density and shape, but no study had considered the submergence ratio, the ratio of the patch width to the channel width and the extent of the patch length. Also, while the most of the previous researches observed and recognized an increase in deposition within the vegetated region, the recent studies had also shown the opposite trend (Bouma et al., 2007; Rominger et al., 2010). However, to our knowledge, none of the existing studies investigates the amount of sediment erosion and deposition, and the parameters which affect the bed morphological changes within and near the finite patches of vegetation, since there are few detailed measurements of morphological patterns near the patch of vegetation, including within-patches.

The objective of this paper is to investigate the flow field and changes in the bed topography near a finite patch in open channel flows with various configurations of the patch (i.e. varying obstruction ratio, length scale of the patch, model patch densities and submergence ratio). To address these topics, we consider simple finite rectangular patches that consist of circular cylinders of $5 \mathrm{~mm}$ with staggered array and place at the mid-channel along a side wall as shown in Fig 1. Laboratory experiments are conducted with various configurations of the model patch with two flow conditions, which are below and above the threshold of sediment entrainment since those lead to quite different patterns of bed morphology near the patch. To characterize the flow field, transverse and longitudinal flow velocities are taken at several positions near and downstream of the patch. The changes in bed topography in and around a finite patch are presented and discussed, and thus, the trend of degree on erosion and deposition near the patch is presented.

\section{Experiment set up}

Laboratory experiments were carried out in a flume of $8 \mathrm{~m}$ long, $L, 0.6 \mathrm{~m}$ wide, $W$, and $0.3 \mathrm{~m}$ deep with wooden side walls as shown in Fig 1. The flume was filled with a $10 \mathrm{~cm}$ layer of sediment of median diameter of $0.9 \mathrm{~mm}$. Water discharge was controlled to be $0.00375 \mathrm{~m}^{3} / \mathrm{s}$ by a manual valve at upstream tank. Initially, a small discharge was drawn to saturate the sand bed in the flume. A plastic mesh screen was installed to minimize effects of turbulence and surface oscillation at the entrance of the upstream channel. Two hydraulic cases were considered with below and above the threshold of sediment motion. In case 1, bed shear stress upstream of the patch was lower than critical bed shear stress, $\tau_{*_{\mathrm{c}}}=0.034$, obtained using Iwagaki's formula, and thus the bed did not change upstream of the patch during experiments. In this case, channel slope was set to $1 / 500$ and the duration of experiments was 5hours. On contrast, in case 2 , the bed shear stress was above the threshold of sediment motion with channel slope of $1 / 200$. The sediment was supplied regularly at upstream end during the experiments. The amount of sediment was estimated using the empirical bedload formula (e.g. Meyer-Peter Muller, 1948) under without-patch. In this condition, experiments were maintained for 2hours. The erosion near the patch is similar to that of cylinder groups and there are many experimental studies on scour around circular cylinders. For flows above the threshold of sediment motion, the scour was developed rapidly whereas for flows below threshold of sediment, it took much longer time to reach equilibrium in which the scour depth was $90 \%$ of equilibrium state after 5 hours. Thus, experiments of Case 2 are carried out for relatively shorter time than that of Case 1 . The experimental conditions are summarized in Table 1.

Table 1. Experimental conditions

\begin{tabular}{|c|c|c|c|c|}
\hline & $Q\left(\mathrm{~m}^{3} / \mathrm{s}\right)$ & Slope & Froude number & $\tau_{*}$ \\
\hline Case1 & 0.00375 & $1 / 500$ & 0.65 & 0.03 \\
\hline Case2 & 0.00375 & $1 / 200$ & 0.82 & 0.06 \\
\hline
\end{tabular}


Rectangular patches were constructed with circular aluminum cylinders of $5 \mathrm{~mm}$ diameter, which are emergent or submerged with a staggered array. The patches were located at the mid-channel, $3.5 \mathrm{~m}$ from upstream of the channel entrance as shown in Fig 1a. The patch density was described by the following two parameters: the patch density, $\lambda\left(\mathrm{m}^{-1}\right)$ that is a frontal area per unit volume, the solid volume fraction, $\phi$. In this study, three patch densities $(\phi=0.013,0.021$ and 0.047 for the emergent patch) were tested, which were corresponding to 0.04 , 0.03 and $0.02 \mathrm{~m}$ of cylinder spacing, respectively. The densities were chosen based on previous studies of Zong and Nepf (2011) and Bennett et al. (2008) who used $\phi=0.019$ to 0.098 and $\phi=0.0004$ to 0.099 , respectively. The ratio of the obstruction width, $W_{v}$, to channel width, $W$ and the influence of the patch lengths, $L_{v}$, were considered. For the emergent patches, $W_{v} / W$ was $1 / 3,1 / 2$ and $2 / 3$ for $W_{v}=20,30$ and $40 \mathrm{~cm}$, respectively, and $L_{v}$ was $0.3,0.5$ and $1.0 \mathrm{~m}$. The non-dimensional flow blockage, $\lambda W_{v}$, which is the product of the patch density and the patch width, was considered, so that the corresponding range was $\lambda W_{\mathrm{v}}=0.65-4.84$. Also, the effect of the submergence ratio $\left(h / h_{\mathrm{v}}=1.38\right.$, where $h_{\mathrm{v}}$ is height of a cylinder) was considered with patch densities. For the submerged patch, $W_{\mathrm{v}} / W$ was $1 / 3$ and $1 / 2$ for $W_{\mathrm{v}}=20$ and 30 $\mathrm{cm}$, respectively, and $L_{\mathrm{v}}$ was $0.5 \mathrm{~m}$. The patch density was varied between $\phi=0.009$ and 0.034 , and the corresponding flow blockage was $\lambda W_{\mathrm{v}}=0.48-2.58$.

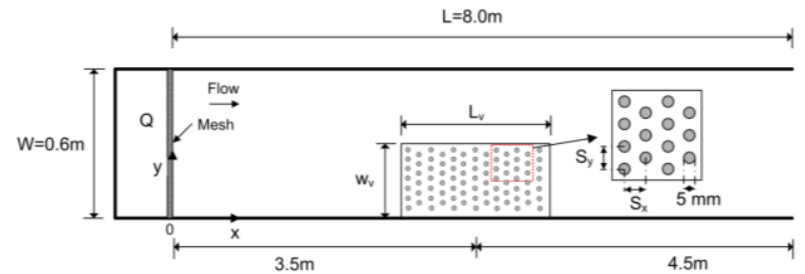

(a) Plan view

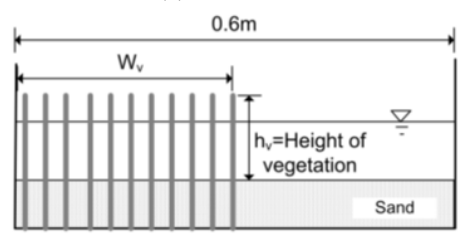

(b) Cross-sectional view with the patch

Fig.1 Schematic diagrams of the laboratory experiment.

To investigate flow fields, velocities were measured using a two dimensional electromagnetic current meter. The probe was mounted above the flume and it was able to be moved along and across the flume. At each point, the averaged velocities were recorded for $30 \mathrm{sec}$. Under the fixed bed, longitudinal velocity profiles of $v$ were measured along the lateral edge of the patch from $x=3.0 \mathrm{~m}$, upstream of the patch to $x=6.0 \mathrm{~m}$, downstream of the patch. Transverse profile surveys were made at several points near and behind the patch. In addition, no velocity was measured within the patch because the patch was covered with a wooden board to fix cylinders, and for submerged condition, the velocity was not measured since cylinders could not be fixed on the bed. On the other hand, under the movable bed, it was difficult to measure velocities due to fact that the probe is able to influence the bed deformation in shallow flows. Thus, we only measured velocities at few points behind the patch to estimate flow rate through the patch. All velocity measurements were made at mid-depth in the vertical direction.

The bed surface was surveyed using the laser bed profiler, which is mounted on the flume. After each experiment, the flow was stopped and then the water was drained slowly. The bed elevation was measured every $10 \mathrm{~cm}$ and $0.4 \mathrm{~cm}$ in longitudinal and transverse directions, respectively, except the region of the patch and close to the patch where the measurement was done every $2 \mathrm{~cm}$ ( $3 \mathrm{~m}$ to $4.5 \mathrm{~m}$ from upstream). The change in bed topography was found from differences between before and after bed elevations.

\section{Results and discussions}

\subsection{Flow field}

Fig 4a shows the flow velocity vectors around and downstream of the patch for $\lambda W_{\mathrm{v}}=3.63\left(W_{\mathrm{v}}=0.3 \mathrm{~m}, \phi=0.047\right)$ under the emergent condition. To clarify the regions near the patch, we divide the channel into five regions (Region (a); upstream of the patch, Region (b); opposite the patch, Region (c); opposite and downstream from the patch, Region (d); the patch, Region (e); behind the patch) as shown in Fig 3.

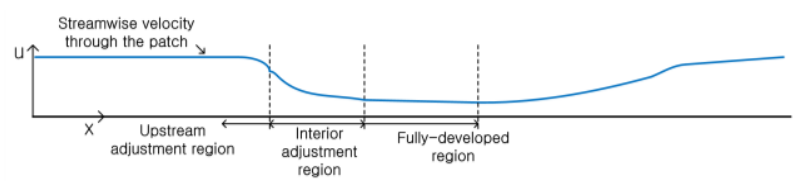

(a) Streamwise velocity along the centerline of the patch

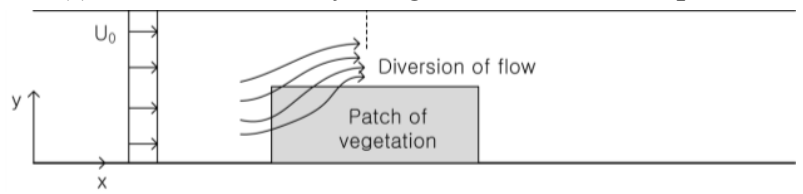

(b) Plan view of flow field in the flume

Fig.2 Conceptual picture for flow field near the patch of vegetation (Rominger and Nepf, 2011).

\begin{tabular}{l|c|c}
\hline$\stackrel{\text { Flow }}{\longrightarrow}$ & Region (b) & Region (c) \\
\cline { 2 - 3 } Region (a) & $\begin{array}{c}\text { Region (d) } \\
\text { Patch of vegetation }\end{array}$ & Region (e) \\
\hline $\mathrm{x}$ &
\end{tabular}

Fig.3 Layout of the region for current vegetated channel.

The approaching flow from the Region (a) is nearly uniform, but velocity profiles are significantly changed with passing through the Region (d). Although, the flow velocity is accelerated in the Region (b) and (c), and the velocity is decelerated after entering the Region (d), but it is laterally uniform in Region (e). Two different velocities are formed downstream of the Region (d) 
due to additional drag of the patch and those are able to create a shear layer. Zong and Nepf (2012) showed that the growth of a shear layer is developed between two different velocities and the peak of turbulent intensity is observed near the shear layer region. Longitudinal velocity profiles of $u$ with three different flow blockages, $\lambda W_{\mathrm{v}}=0.98,1.62$ and $3.63\left(W_{\mathrm{v}}=0.3 \mathrm{~m}, \phi=\right.$ $\left.0.013 ; W_{\mathrm{v}}=0.3 \mathrm{~m}, \phi=0.021 ; W_{\mathrm{v}}=0.3 \mathrm{~m}, \phi=0.047\right)$ are presented along the centre of the Region (b) and (c) $(y=0.45 \mathrm{~m})$, and the Region (c) ( $y=0.15 \mathrm{~m})$ in Fig $4 \mathrm{~b}$ and c, respectively. Longitudinal velocity increases at $x=3.3 \mathrm{~m}$ in the Region (b) and those have peak values at $x=4.0 \mathrm{~m}$ regardless of the flow blockage (Fig 4b). The flow velocity of $u$ in the Region (b) and (c), increases with increasing the flow blockage. On the other hand, in the Region (e), longitudinal velocity is considerably decelerated, compared to the Region (c) in Fig 4c, for which the longitudinal velocity decreases as the patch density increases. In fact, the flow is not able to penetrate a solid obstruction with same width, so that the flow velocity becomes greater near the obstruction and it has negative value behind the solid obstruction due to a recirculation zone such as spur dikes (Koken and Constantinescu, 2008).

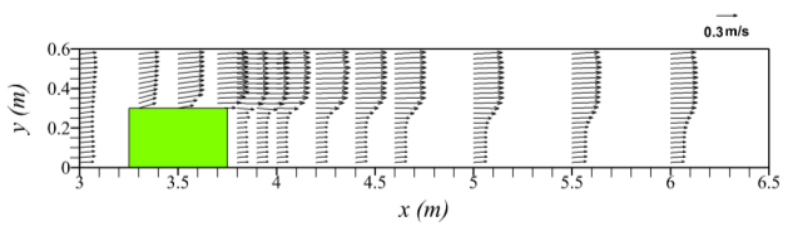

(a) velocity vector for the patch with $\lambda W_{\mathrm{v}}=3.63$

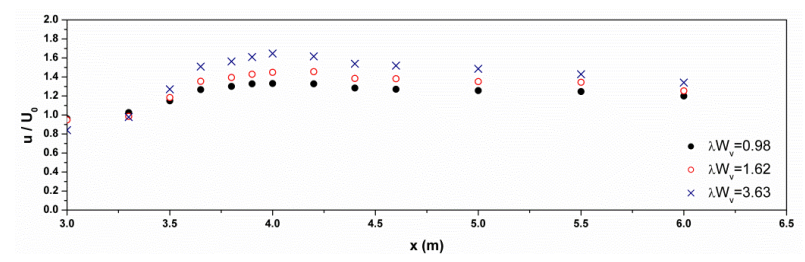

(b) Longitudinal velocity profiles of $u$ at $y=0.45 \mathrm{~m}$

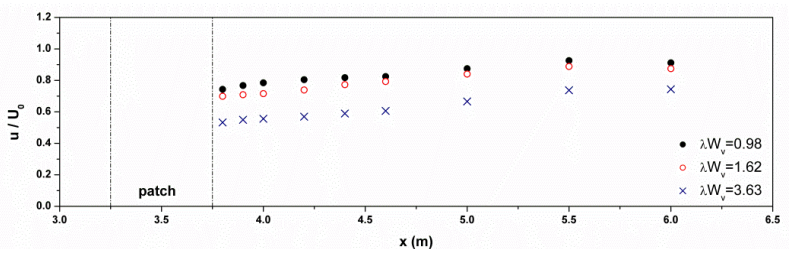

(c) Longitudinal velocity profiles of $u$ at $y=0.15 \mathrm{~m}$

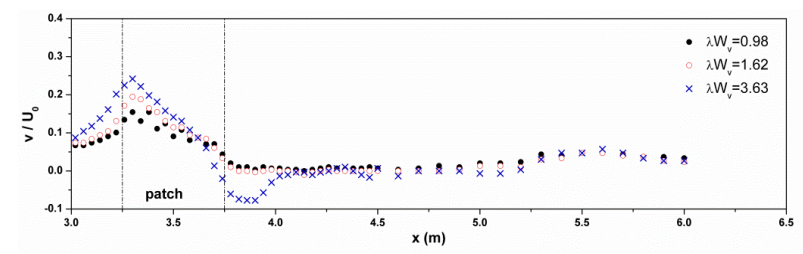

(d) Transverse velocity of $v$ along the longitudinal intersection at the edge of the patch at $y=0.3 \mathrm{~m}$

Fig.4 Velocity vector and profiles

Thus, unlike the flow with a solid obstruction, for the porous patch, the flow is able to move through or near the patch and it depends on the patch density. In other words, as the patch density becomes higher, the flow rate through the Region (d) decreases since the greater flow rate is diverted away from the Region (d). The acceleration of $u$ in the Region (b) and (c), and the deceleration of $u$ in the Region (e) are accompanied by an increase in diversion of flow from the Region (d) in Fig $4 \mathrm{~b}$ and $\mathrm{c}$. Transverse velocity of $v$ along the longitudinal intersection at the edge of the patch at $y=0.3 \mathrm{~m}$ are shown in Fig $4 \mathrm{~d}$. The transverse velocity shows an increasing behavior from the Region (a). It has a maximum value near the leading edge of the Region (d), and then decreases to the end of the Region (d). In the Region (e), the transverse velocity is nearly zero and it forms a uniform flow. For the flow blockage of 3.63, the negative transverse velocity is observed directly behind the Region (d). The transverse velocity of $v$ near the leading edge, which is associated with diversion of flow, increases with increasing the flow blockage due to higher drag. Thus, the higher flow blockage leads to higher diversion of flow, so that it causes greater flow acceleration in the Region (b) and (c) and it induces more deceleration of flow in the Region (d) and (e). Even though we do not measure the velocity in the Region (a) and (d), it is expected that the flow velocity begins to decrease from the Region (a) and it decreases continuously until the end of diversion of flow through the Region (d) (Zong and Nepf, 2011; Rominger and Nepf, 2011). Rominger and Nepf (2011) defined upstream adjustment region as shown in Fig 2, where the flow velocity through the patch begins to decelerate from upstream of the patch with distance of the patch width, $W_{\mathrm{v}}$, due to the increase in pressure. Moreover, they defined the interior adjustment region as shown in Fig 2, where flow diversion begins upstream of the patch and continues with some distance into the patch, which is end of flow divergence. They found that for the flow blockage, $\lambda W_{\mathrm{v}}<2$, the length of the interior adjustment region is $2 / C_{D} \lambda$, whereas for the high flow blockage $\left(\lambda W_{\mathrm{v}} \geq 2\right)$, it is equal to the patch width, $W_{v}$. Here, $C_{\mathrm{D}}$ is assumed to be 1.0 (Rominger and Nepf, 2011). Thus, for $\lambda W_{\mathrm{v}}=1.62$ and 3.63 , the fully-developed region is formed within the Region (d) beyond $x=3.62 \mathrm{~m}$ and $3.55 \mathrm{~m}$, respectively, whereas for $\lambda W_{\mathrm{v}}=$ 0.98 , the interior adjustment region is beyond the Region (d). It means the diversion of flow occurs until the end of the Region (d). The upstream adjustment region and the interior region have influences on bed morphological changes by affecting erosion and deposition within and near the Region (d). The effect of upstream and interior adjustment region on the bed morphology will be described in section 3.3.

\subsection{Flow below the threshold of sediment motion}

\subsubsection{Bed elevation}

We first consider the condition in which the shear stress is below the critical shear stress (Case 1). The bed morphological changes with three different patch densities for the emergent 
condition and a high patch density for the submerged condition are depicted in Fig 5. It can be seen that local erosion occurs in the Region (b) and (c) due to acceleration of flow and elevated turbulence levels, causing additional drag. The bed morphological changes are similar to each other due to similar flow patterns in response to the patches. However, the magnitude of erosion observed in the Region (b) and (c) and also near the leading edge of the Region (d) is significantly changed with an increase in the flow blockage. From comparisons between Fig 5a, b and c, the local scour depth increases as the flow blockage becomes higher (higher patch density) due to fact that a higher flow blockage accompanies a

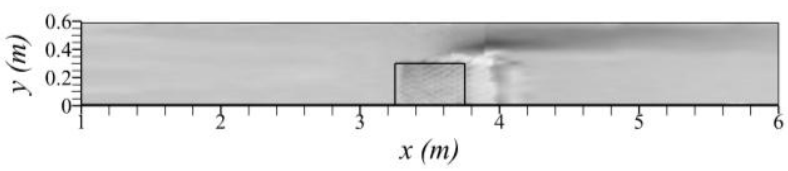

(a) $\lambda W_{\mathrm{v}}=0.98$ (emergent)

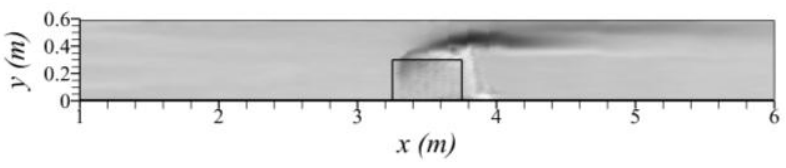

(b) $\lambda W_{\mathrm{v}}=1.61$ (emergent)

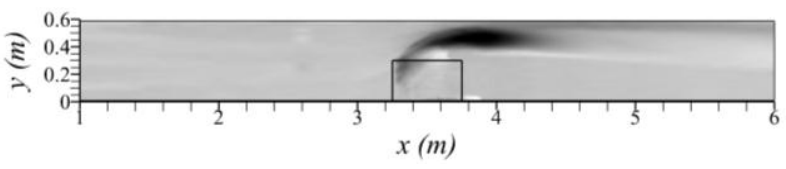

(c) $\lambda W_{\mathrm{v}}=3.63$ (emergent)

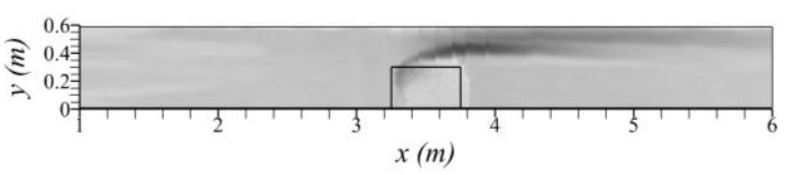

(d) $\lambda W_{\mathrm{v}}=2.58$ (submerged)

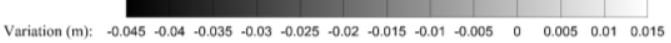

Fig.5 Bed elevation. Flow is left to right and solid lines denote the patch.

higher diversion of flow. The enhanced flow velocities cause more erosion in the Region (b) and (c). For the high flow blockage in Fig $5 \mathrm{c}$, the local scour becomes more pronounced. For lower blockages $\left(\lambda W_{\mathrm{v}}=0.98, \phi=0.013 ; \lambda W_{\mathrm{v}}=1.62, \phi=\right.$ $0.021)$, small-scale scour appears in the vicinity of the cylinders inside the Region (d) and then sediment is transported downstream. Thus, deposition occurs just beyond the Region (d) but it is observed in the initial stage. It also moves slightly downstream, generating small-scale turbulence by each cylinder just behind the Region (d), which is quickly dissipated (Zong and Nepf, 2012). For the high blockage ( $\left.\lambda W_{\mathrm{v}}=3.63, \phi=0.047\right)$, however, sediment deposition does not occur in the Region (e) because most of the flow rate is diverted away from the Region (d) and thus, the flow is significantly decelerated within the Region (d), even though small deposition is observed near the lateral edge of the Region (d). In Fig 5d, the bed elevation is shown for the high blockage $\left(\lambda W_{\mathrm{v}}=2.58, \phi=0.034\right)$ under the submerged condition. From comparing with the emergent one, the spatial patterns of bed morphology are similar, but the magnitude of erosion in the Region (b) and (c) is lower for the submerged case because the flow rate passing through the Region (d) is higher than the flow rate in the emergent case. In other words, in the submerged case, the flow acceleration decreases in the Region (b) and (c), even though the number of cylinders of the submerged patch is identical to that of the emergent patch. This implies that as the submergence ratio increases, the diversion of flow decreases because the patch density or the flow blockage decreases. Thus, the bed shear stress decreases in the in the Region (b) and (c), reducing the velocity and the turbulence intensity.

\subsubsection{Longitudinal bed profiles}

Fig 6 shows laterally-averaged longitudinal bed profiles in two regions where the Region ( I ) is laterally averaged from right side wall to the lateral edge of the patch $(y=0.2,0.3$ and $0.4 \mathrm{~m}$ ) and the Region (II) is laterally averaged over the remaining area. In this figure, dash lines denote the patches.

It can be seen in Fig 6 that although the bed is not changed in upstream part of the patch, erosions are observed in the Region (II), which increase with increase in the flow blockage, and local scours occur near the leading edge (Region ( I )). Local scour begins at the leading edge of the patch and grows with distance inside the patch about $0.08 \mathrm{~m}$ from the leading edge. Then, the scour depth decreases until the end of the patch except for the high blockage $\left(\lambda W_{\mathrm{v}}=2.38, \phi=0.047\right)$ in which the scour depth is sharply reduced. Local scours observed in the experiments take place inside the patch, unlike a solid obstruction that the scour occurs at the front of solid one and the scour area is extended upstream of it. This is attributed to several mechanisms, mainly causing the diversion of flow, the horseshoe vortices and the turbulence. Firstly, the diversion of flow occurred near the leading edge, in which the patch of the higher blockage had higher diversion of flow, which is responsible for carrying more sediment away from the area near the leading edge of the patch. Secondly, this phenomenon is similar to scour patterns observed around pile groups in the laboratory experiments or the field (Rominger and Nepf, 2010). Several experimental series were conducted to investigate the scouring system around pile groups (Ataie-Ashtiani and Beheshti, 2006). They showed as the cylinder spacing is large enough, the scouring patterns are similar to an isolated cylinder. However, as long as the flow structure from the cylinders interfered from the other cylinders longitudinally or laterally, turbulence intensity is increased with decreasing cylinder spacing. Also, for small cylinder spacing, the size of the horseshoe vortices close to the cylinders increases and an enhanced local flow is induced between two neighboring 
cylinders (Ataie-Ashtiani and Beheshti 2006). The scouring depth is strongly affected by such flow structures. Bouma et al. (2007) observed similar bed morphological changes in the field. They found the high within-patch eroded region near the leading edge of dense patch, which was placed on sand bed in the intertidal flat. Similarly, the scouring began near the front of the patch and it continued inside the patch. Then, deposition occurred just behind the scoured area. For the patch with submerged cylinders, $\lambda W_{\mathrm{v}}=1.2, \phi=0.015$, in Fig $6 \mathrm{c}$, the local erosion observed near the leading edge of the patch (dash dot line) becomes lower than that scoured under emergent condition ( $\lambda W_{\mathrm{v}}=1.62$, solid line). This may be because the size of horseshoe vortices decreases and the vortex shedding becomes weaker as the submergence ratio increases. The diversion of flow also decreases with decreasing the flow blockage. Indeed, the flow through submerged cylinders is very complex because spanwise rollers and vortices are generated at the top of the cylinders, producing an inflection of the streamwise velocity. The coherent structures play an important role for mass and momentum exchange between two regions and those affect the sediment transport. However, the local scouring does not seem to be influenced by such complex vortex structures because the scour depth of submerged one is lower than that of emergent one.
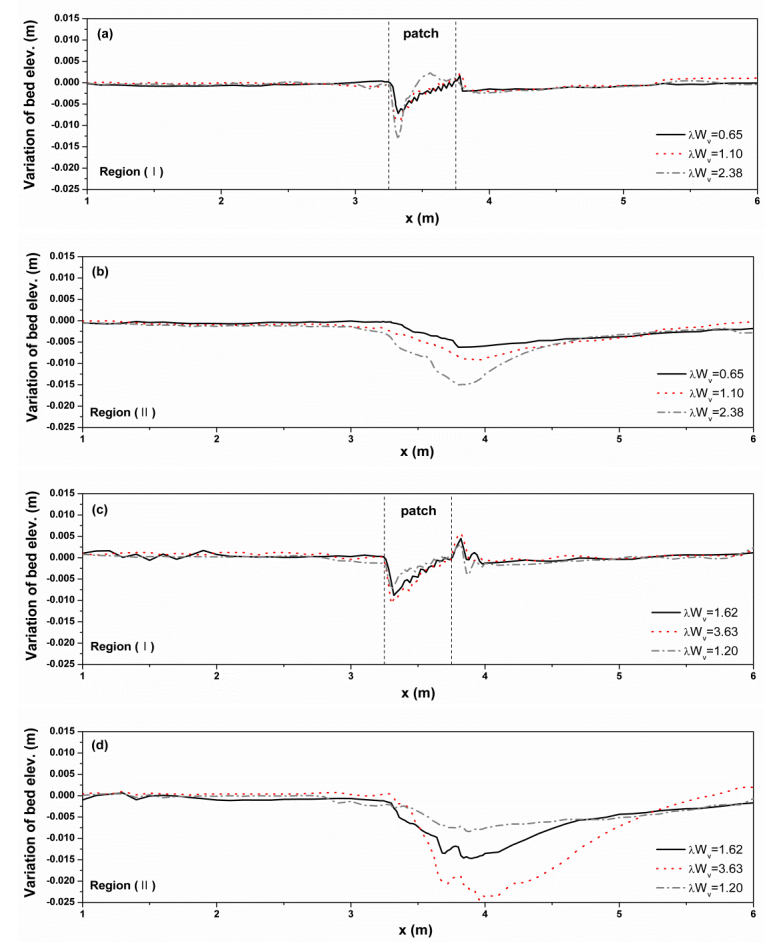

Fig.6 Laterally averaged longitudinal bed profiles; (a) Region

( I ) with $\lambda W_{\mathrm{v}}=0.65,1.10$ and $2.38\left(W_{\mathrm{v}}=0.2 \mathrm{~m}\right)$, (b) Region

(II) with $\lambda W_{\mathrm{v}}=0.65,1.10$ and $2.38\left(W_{\mathrm{v}}=0.2 \mathrm{~m}\right)$, (c) Region

( I ) with $\lambda W_{\mathrm{v}}=1.62,3.63$ and $1.20\left(W_{\mathrm{v}}=0.3 \mathrm{~m}\right)$, (d) Region

(II) with $\lambda W_{\mathrm{v}}=1.62,3.63$ and $1.20\left(W_{\mathrm{v}}=0.3 \mathrm{~m}\right)$.

\subsubsection{Scour in response to the patch}

Fig $7 \mathrm{a}$ and $\mathrm{b}$ show the maximum scour depth, $d_{s}$, normalized by cylinder diameter, $d$, according to the flow blockage for both emergent and submerged conditions. In these figures, linear lines are fit to maximum scour depth of the emergent and submerged data to emphasize difference between them.

The maximum scour depth in Fig 7a is corresponding to the Region (b). It can be seen that the scour depth increases as the flow blockage increases. For the lower blockage $\left(\lambda W_{\mathrm{v}}<1.0\right)$, the scour depth is similar between emergent and submerged cases, whereas it is shown that, for the flow blockage with $\lambda W_{\mathrm{v}} \geq 1.0$, the scour depth observed in the emergent condition is deeper than that of the submerged condition. The maximum scour depth observed in the Region (b) not only increases with an increase in the flow blockage but also it is significantly influenced by the submergence ratio. Fig $7 \mathrm{~b}$ shows the maximum local scour depth observed near the leading edge of the Region (d) with respect to the flow blockage for both emergent and submerged conditions. It can be seen that the trend of the local scour depth increases with an increase in the flow blockage in both conditions, whereas the magnitude of local scour is diminished as the submergence ratio increases. As a result, the local scouring occurred near the leading edge increases with increasing the flow blockage, $\lambda W_{\mathrm{v}}$. The fact supports that the relatively stronger flow (i.e. diversion of flow, horseshoe vortices and turbulence) is induced with an increase in the flow blockage.

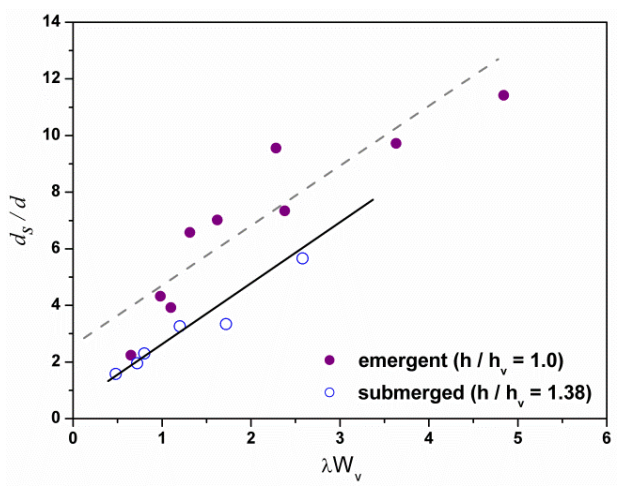

(a) Maximum scour depth

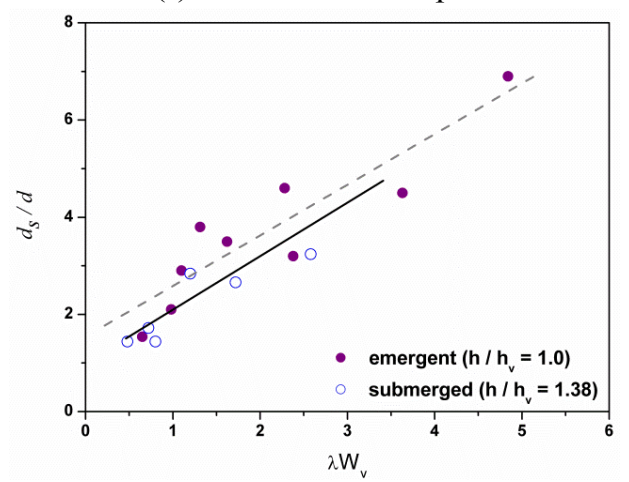

(b) Maximum scour depth at the leading edge of the patch

Fig.7 Scour depth according to the flow blockage under the flow below the threshold of sediment motion.

3.3 Flow above the threshold of sediment motion 


\subsubsection{Bed elevation}

Fig 8 depicts the bed morphological changes for three patch densities under the emergent condition and a high patch density under the submerged condition. Unlike experiments of the previous section (Case 1), the flow condition is above the threshold of sediment motions $\left(\tau_{*_{\mathrm{c}}}<\tau_{*}\right)$, so sediment is transported from the Region (a). The bed deformations appear in the Region (a) and they migrate toward the downstream direction. Then, the bedforms pass through the Region (b) or (d), and the sediment passing through the Region (b) is deposited near the relatively low bed shear stress region along the lateral edge of the Region (d), which is consistent with the wake region. The shear layer due to difference velocity between Region (c) and (e) is created, which forms coherent vortices in that region. Those induce enhancement of lateral sediment transport and thus sediment is deposited near relatively low bed shear region along the edge of the patch. Similarly, the erosion takes place in the Region (b) and (c) due to diversion of flow and it increases with the increase in the flow blockage. It can be seen in Fig 8 that sediment deposition is observed in the Region (a) with distance about $0.25 \mathrm{~m}$ regardless of the flow blockage or the submergence ratio. Far upstream of the patch, the flow is uniform that is not affected by the patch. As the flow approaches the Region (d), the flow velocity becomes low due to an increase in pressure and then, deposition occurs near the Region (a) due to reduction of bed shear stress. The deposition regions correspond to the upstream adjustment region (see Fig 2). We first discuss the results of the emergent condition in Fig 8a, $\mathrm{b}$ and $\mathrm{c}\left(\lambda W_{\mathrm{v}}=0.65, \phi=0.013, \lambda W_{\mathrm{v}}=1.1, \phi=0.021, \lambda W_{\mathrm{v}}=2.38, \phi=\right.$ 0.047). Unlike the local scouring near the leading edge of the Region (d) observed in the flow below the critical value of sediment motion (Section 3.2), sediment is deposited in the Region (d) and (e). Sediment is entered passing through the leading edge of the Region (d), and then sediment is either transported further downstream or diverted away from the Region (d) due to diversion of flow. For the low flow blockage ( $\left.\lambda W_{\mathrm{v}}=0.65, \phi=0.013\right)$, deposition takes place in the Region (d) and (e) without the local erosion, although small-scale erosion is observed in the vicinity of cylinders in the Region (d), which is negligible. It is found that, for the higher blockage, sediment is deposited within and near the Region (d), and the local erosion is observed near the leading edge of the Region (d). While the approaching velocity increases, the local scouring is considerably weakened due to the increase in sediment input from the Region (a) in comparison with that shown in section 3.2. Fig $8 \mathrm{c}$ and $\mathrm{d}$ show that bed change patterns under the submerged condition are similar to that observed in the emergent condition. However, the local scour becomes lower near the leading edge of the Region (d), and sediment deposition within the submerged patch increases since diversion of flow is diminished with a decrease in the flow blockage. For the emergent patch, eddies are generated in the turbulent wakes of individual cylinders, whereas the submerged patch not only forms eddies behind the cylinders but also generates shear layer above the top of the cylinders. It is shown, however, that the shear layer generated near the top of cylinders does not affect sediment transport in our experiments. Nepf (1999) described that the wake turbulence decreases with the increase in the submergence ratio, so that it reflects that the local erosion is weakened near the leading edge and in the Region (d). In other words, deposition becomes higher in and near the Region (d) as the submergence ratio becomes larger. It is found in Fig 8 that the distinct region is formed in the Region (e), where sediment transport does not take place as a result of the reduction of bed shear stress due to additional patch drag. It indicates that the von Karman vortices or recirculation zone are not formed by the patch and it continues to the end of the measured position $(x=$ $6.0 \mathrm{~m})$. As seen in Fig 4, the velocity is distinctly recovered without disturbance and the transverse velocity along the edge of the patch is uniform downstream of the patch, which supports that there are no recirculation and vortices behind the patch. In addition, Nicolle and Eames (2011) presented that those occur when the solid volume fraction is larger than 0.15 , whereas we considered it smaller than 0.05 .

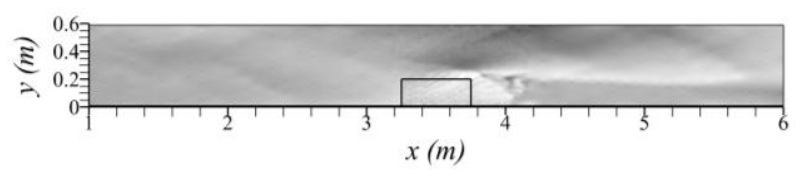

(a) $\lambda W_{\mathrm{v}}=0.65$ (emergent)

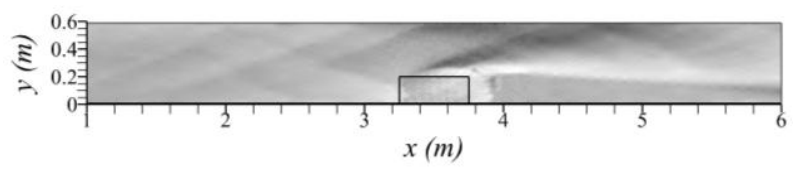

(b) $\lambda W_{\mathrm{v}}=1.1$ (emergent)

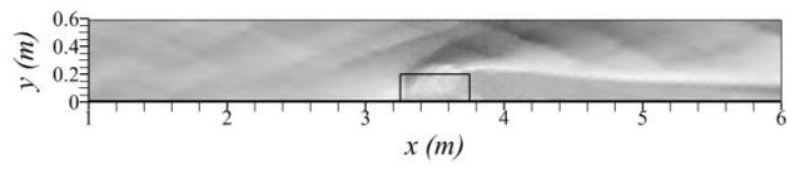

(c) $\lambda W_{\mathrm{v}}=2.38$ (emergent)

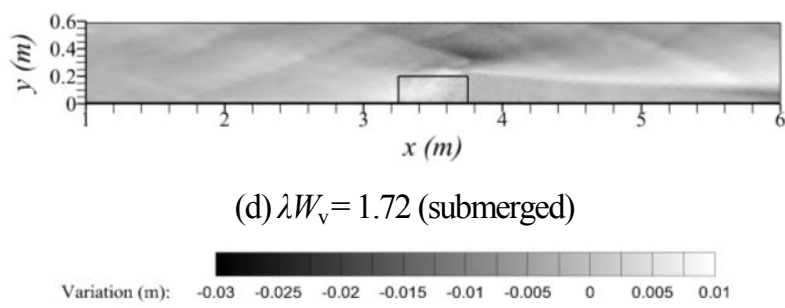

Fig.8 Bed elevation. Flow is left to right and solid lines denote the patch.

\subsubsection{Longitudinal bed profiles}

Fig 9 shows laterally-averaged longitudinal bed profiles for two regions through the Region ( I ) and the Region (II), relatively. The dash lines denote boundaries of the patch and the dash dot lines are the interior adjustment regions, which are 
determined by scaling as explained in section 3.1. Sediment deposition begins upstream of the patch with distance about that slightly larger than the upstream adjustment region $\left(=W_{\mathrm{v}}\right)$. From the leading edge of the patch $(x=3.25 \mathrm{~m})$, scour begins sharply over a finite distance toward downstream, and it becomes more pronounced with the increases in the flow blockage, after which deposition occurs within or behind the patch. It can be seen in Fig 9 that for $\lambda W_{\mathrm{v}}>1.0$, the scoured area is observed within the range of the interior adjustment regions and scouring depth increases with the increase in the flow blockage.
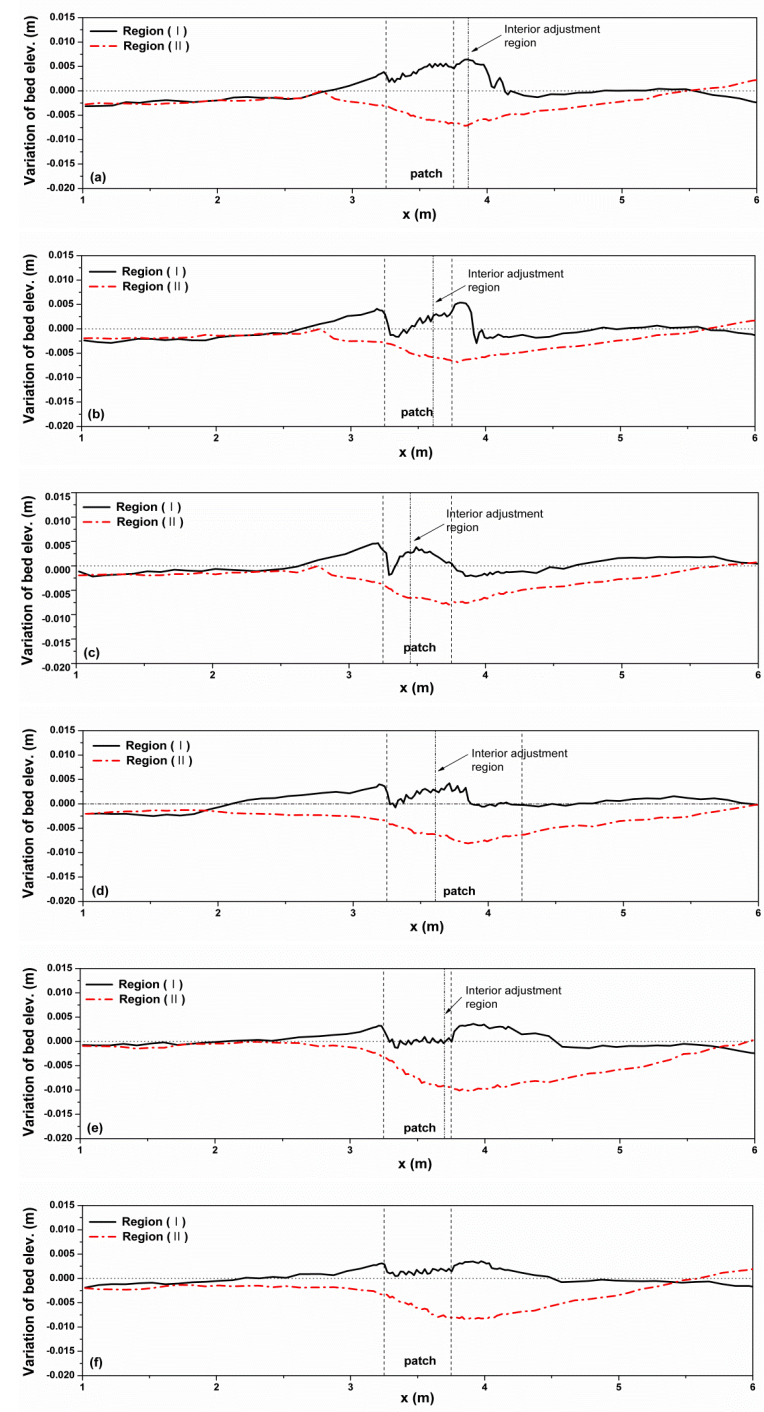

Fig.9 Laterally averaged longitudinal bed profiles; (a) $\lambda W_{\mathrm{v}}=$ $0.65\left(W_{\mathrm{v}}=0.2 \mathrm{~m}, L_{\mathrm{v}}=0.5 \mathrm{~m}, \phi=0.013\right),(\mathrm{b}) \lambda W_{\mathrm{v}}=1.1\left(W_{\mathrm{v}}=\right.$ $\left.0.2 \mathrm{~m}, L_{\mathrm{v}}=0.5 \mathrm{~m}, \phi=0.021\right),(\mathrm{c}) \lambda W_{\mathrm{v}}=2.38\left(W_{\mathrm{v}}=0.2 \mathrm{~m}, L_{\mathrm{v}}=\right.$ $0.5 \mathrm{~m}, \phi=0.047),(\mathrm{d}) \lambda W_{\mathrm{v}}=1.1\left(W_{\mathrm{v}}=0.2 \mathrm{~m}, L_{\mathrm{v}}=1.0 \mathrm{~m}, \phi=\right.$ $0.021),(\mathrm{e}) \lambda W_{\mathrm{v}}=1.62\left(W_{\mathrm{v}}=0.3 \mathrm{~m}, L_{\mathrm{v}}=0.5 \mathrm{~m}, \phi=0.021\right),(\mathrm{f})$

$$
\lambda W_{\mathrm{v}}=1.2\left(W_{\mathrm{v}}=0.3 \mathrm{~m}, L_{\mathrm{v}}=0.5 \mathrm{~m}, \phi=0.015\right) .
$$

In particular, for $\lambda W_{\mathrm{v}}=1.62$, the erosions are found over the entire length of the patch and then sediment is deposited directly behind the patch. In Fig 9d, even though the length of the patch is two times larger than that shown in Fig 9b, it does not influence the bed morphological changes inside the patch, which are consistent with each other. This result implies that the length scale has negligible effects if the patch length is longer than the interior adjustment region. For $\lambda W_{\mathrm{v}}<1.0$ (the lowest blockage), the local scour becomes less pronounced near the leading edge of the patch, although the interior adjustment region is beyond the patch. This is attributed to the fact that the effect of diverging flow is considerably reduced as the flow blockage decreases.

For these patches of $\lambda W_{\mathrm{v}}>1.0$, the interior adjustment region is in a good agreement with scoured areas within the patch, which indicates that the erosion within the patch takes place throughout the interior adjustment region, after which sediment is deposited just behind that region. The interior adjustment region indicates that the flow deceleration, which begins from upstream of the patch in response to flow resistance by the patch drag, continues to the end of diversion of flow, after which the flow is fully developed with the low velocity if the patch length is long enough. On the other hand, Zong and Nepf (2011) showed that the turbulence increases rapidly from the leading edge of the patch, which is associated with cylinder-wakes, and the turbulence levels increase as the patch density increases, even though the flow velocity is reduced continuously along the streamwise direction. The elevated levels of turbulence are reflected in the increase in the scouring depth near the leading edge of the patch, and sediment scoured within the patch is accumulated just behind the region or is diverted away from the region. Thus, the scoured bed within the patch supports high bottom shear stress region caused by elevated turbulence levels in comparison with non-vegetated channel at the same flow condition. Zong and Nepf (2011) observed the reduced deposition in the region due to elevated turbulence. From above discussion, we found that the upstream and interior adjustment regions are able to describe important characteristics of bed morphological changes within and near the patch. In Fig 9f, the laterally-averaged longitudinal bed profile is depicted for the submerged condition ( $\left.W_{\mathrm{v}}=1.2, \phi=0.021\right)$. Overall, the bed morphological changes of the submerged data are similar to that of the emergent data (Fig 9e). The bed is eroded from the leading edge of patch and it continues to the end of the patch. However, the scoured bed within the patch is less pronounced in comparison with emergent data in Fig 9e due to diminished turbulence levels with an increase in the submergence ratio. For the submerged condition, we could not indicate the interior adjustment region because this scaling is only available for emergent patches.

\subsubsection{Scour in response to the patch}

Fig 10 shows the maximum scour depth versus the flow blockage for both emergent and submerged conditions. It can be seen that the maximum scour observed in the Region (b) increases with an increase in the flow blockage regardless emergent or submerged condition. This is a similar trend to the result in which the flow condition is below the threshold of 
sediment motion in the section 3.2, which indicates that the scour depth increases almost linearly with the flow blockage, but it seems to be not uniform. This is attributed to fact that the scour depth is changed due to the transition stage of sediment transport. Indeed, for the flow above the critical value of sediment motion, the scour depth fluctuates with time due to the migrations of bedforms such as bars or dunes (Ballio et al., 2010). In our experiments, we observed that the formation of alternating bar patterns is formed and migrated from the Region (a) in Fig 8. This seems to be the reason why the trend in Fig 10 is not uniform as the bars pass through the Region (b) and (c).

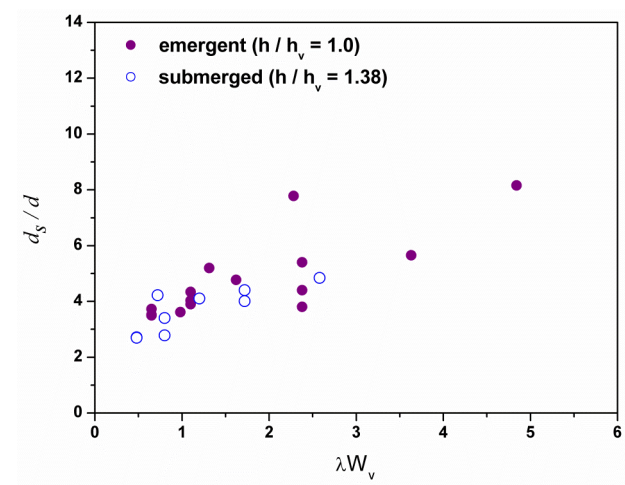

Fig.10 Scour depth according to the flow blockage under the flow above the threshold of sediment motion.

\subsubsection{Deposition in response to the patch}

In the experimental data with the flow which exceeds critical value of sediment threshold, sediment deposition is observed in the Region (d) and (e). Fig 11 shows the ratio of depositional volume to input sediment volume according to the ratio of the flow rate through the Region (d), $Q_{v}$ to the total flow rate, $Q$.

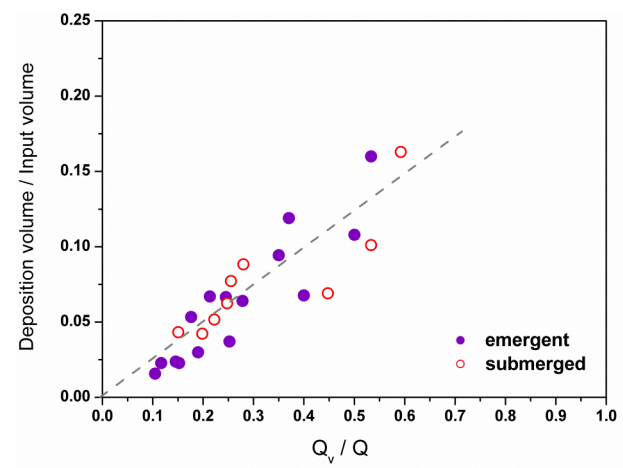

Fig.11 Ratio of depositional volume to input sediment according to the flow rate through the patch.

The amount of deposition is only considered within and behind the patch, whereas the sediment deposited along the lateral edge and downstream of the Region (d) is excluded. The ratio of deposition increases almost linearly with the increase in the ratio of the flow rate through the Region (d) regardless of emergent / submerged conditions within present hydraulic conditions. It is shown that for the same flow condition, the higher patch densities experience much smaller sediment accumulation than those of the low patch densities in the Region (d) and (e). As the flow rate through the Region (d) increases (i.e. the flow velocity increases behind the patch as shown in Fig 4), the diversion of flow from the Region (d) decreases. Therefore, as the patch density becomes denser, sediment is not transported into the Region (d) of downstream and the greater sediment volumes are carried away from the Region (d) since the more flow rate is diverted away from the Region (d). It is found that a similar trend appears in that of the submerged condition and thus, the ratio of the flow rate through the patch versus the total flow rate can be a good predictor for sediment deposition volume in the Region (d) and (e) as the flow condition exceeds the threshold of sediment motion.

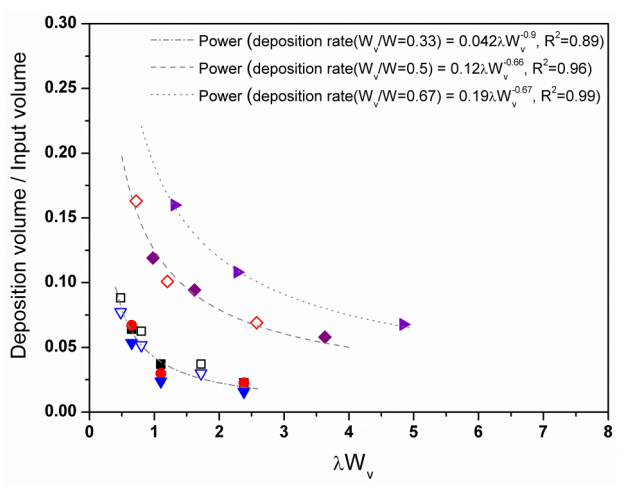

Fig.12 Ratio of depositional volume to input sediment according to the flow rate through the patch where the solid symbols denote data of the emergent patches and the empty symbols denote data of the submerged patches ( when $W_{\mathrm{v}}=0.2$ $\mathrm{m}$ and $L_{\mathrm{v}}=0.3 \mathrm{~m}$, the data symbol is square; when $W_{\mathrm{v}}=0.2 \mathrm{~m}$ and $L_{\mathrm{v}}=0.5 \mathrm{~m}$, the data symbol is circle; when $W_{\mathrm{v}}=0.2 \mathrm{~m}$ and $L_{\mathrm{v}}=1.0 \mathrm{~m}$, the data symbol is nabla; when $W_{\mathrm{v}}=0.3 \mathrm{~m}$ and $L_{\mathrm{v}}=$ $0.5 \mathrm{~m}$, the data symbol is diamond; when $W_{\mathrm{v}}=0.4 \mathrm{~m}$ and $L_{\mathrm{v}}=$ $0.5 \mathrm{~m}$, the data symbol is right-triangle.)

Fig 12 shows the ratio of deposition volume to input sediment volume according to the flow blockage. In this figure, the observed data of emergent ones are presented together with those of submerged ones. The experimental data are regressed for each obstruction ratio using power law and these are drawn on the data to distinguish between them. It can be seen that the ratio of deposition in the Region (d) and (e) is clearly a function of the flow blockage regardless of submergence ratio. The flow blockage is strongly associated with the diversion of flow, so that the diversion of flow becomes higher as the flow blockage increases, which is reflected in much more loss of sediment volume from the leading edge of the Region (d). Thus, the sediment possible to go into the Region (d), after which it is accumulated in the Region (d) or (e), is diminished. It is found that the obstruction ratio shows a much greater influence on the ratio of deposition volume than the length scale of the patch. The length scale of the patch shows negligible effects in both emergent and submerged conditions as shown in Fig 12. 


\section{Conclusions}

The bed morphological changes in response to a finite patch consisting of the emergent and submerged cylinders in open channel were investigated using laboratory experiments. Two hydraulic conditions, which were below and above the threshold of sediment motion, were tested with various configurations of the patch as well as the submergence ratio. The finite patch in open channel flows altered flow patterns, which significantly reduced the mean velocities in and behind the patch and caused the diversion of flow from the patch, depending on the patch density. The bed morphological changes near the finite patch were highly influenced by altered flows.

When the bed shear stress was below the threshold of motion (Case 1), the erosion was primarily observed not only opposite the patch due to the acceleration of flow but also near the leading edge of the patch because of elevated turbulence and the diversion of flow. We found that the scour depth observed both opposite the patch and near the leading edge was strongly dependent on the flow blockage, i.e., the product of obstruction ratio and the patch density. The submergence ratio affected the magnitude of erosion at both regions, which was reduced as the submergence ratio increased since the turbulence levels and diversion of flow were weakened. The degree of the scouring depth increased with the flow blockage.

For Case 2, in which the bed shear stress exceeded the critical values of sediment motion, unlike the case 1 , the sediment deposition as well as the erosion was observed near the finite patch in the open channel flows. While the trend of erosion was similar to that of case 1 , the difference between the emergent and submerged patch was not evident. The sediment deposition began upstream of the patch, and local erosion occurred from the leading edge of the patch to downstream, after which deposition was observed just beyond the scoured region that was consistent with the interior adjustment region. It was found that sediment deposition near the finite patch was strongly influenced by the flow blockage, so that as the patch density increased, the deposition rate became lower since higher patch densities led to higher diversion of flow, and thus it carried away much more sediment loading from the patch. Also, greater influences on deposition near the patch were the obstruction ratio and the ratio of flow rate through the patch, whereas the length scale of the patch had a negligible effect on sediment deposition.

\section{References}

1) Ataie-Ashtiani, B. and A.A. Beheshti.: Experimental investigation of clear-water local scour at pile groups. $J$. Hydraul. Eng. 132(10), pp.1100-1104, 2006.

2) Ballio, F., Radice, A. and Dey, S.: Temporal scales for live-bed scour at abutments. J. Hydraul. Eng. 136(7), pp.395-402, 2010.
3) Bennett, S., Pirim, T. and Barkdoll, B.: Using simulated emergent vegetation to alter stream flow direction within a straight experimental channel. Geomorphology. 44, pp.115-126, 2002.

4) Bennett, S., Wu, W., Alonso, C. and Wang, SSY.: Modeling fluvial response to in-stream woody vegetation: implications for stream corridor restoration. Earth Surf. Process. Landforms. 33, pp.890-909, 2008.

5) Bouma, T, J., van Duren, L, A., Temmerman, S., Claverie, T., Blanco-Garcia, A.,Ysebaert, T. and P M J Herman.: Spatial flow and sedimentation patterns within patches of epibenthic structures: combining field, flume and modeling experiments. Cont. Shelf. Res. 27, pp.1020-1045, 2007.

6) Choi, S-U. and Kang, H.: Numerical investigations of mean flow and turbulence structures of partly-vegetated open-channel flows using the Reynolds stress model. $J$. Hydraul. Res. 44(2), pp.203-217, 2006.

7) Koken, M. and Constantinescu, G.: An investigation of the flow and scour mechanisms around isolated spur dikes in a shallow open channel: 1 . Conditions corresponding to the initiation of the erosion and deposition process. Water Resour. Res. 44; W08406, 2008.

8) Leu, J, M., Chan, H, C., Jia, Y., He, Z. and Wang, S S Y.: Cutting management of riparian vegetation by using hydrodynamic model simulations. Adv. Water Resour. 31, pp.1299-1308, 2008.

9) Mayer-Peter, E. and Muller, R.: Formulas for bed-load transport. Proceeding of 2nd Congress, IAHR, Stockholm, 1948.

10) Millar, R, G.: Influence of bank vegetation on alluvial channel patterns. Water Resour. Res. 36(4), pp.1109-1118, 2000 .

11) Nepf, H, M. and Vivoni, E, R.: Flow structure in depth-limited vegetated flow. J. Geophys, Res. 105(28), pp.547-557, 1999.

12) Nicolle, A. and Eames, I.: Numerical study of flow through and around a circular array of cylinders. J. Fluid Mech. 679, pp.1-31, 2011.

13) Rominger, J, T., Lightbody, A. and Nepf, H, M.: The Effects of Added Vegetation on Sand Bar Stability and Stream Hydrodynamics. J. Hydraul. Eng. 136(12), pp.994-1002, 2010.

14) Rominger, J, T. and Nepf, H, M.: Flow adjustment and interior flow associated with a rectangular porous obstruction, J. Fluid Mech. 680, pp.636-659, 2011.

15) Zong, L. and Nepf, H, M.: Spatial distribution of deposition within a patch of vegetation. Water Resour. Res. 47, W03516, 2011

16) Zong, L. and Nepf, H, M.: Vortex development behind a finite porous obstruction in a channel. J. Fluid Mech. 691,pp. 368-391, 2012.

(Received March 18, 2013) 